\title{
Radial Basis Function in Artificial Neural Network for Prediction of Bankruptcy
}

\author{
Alireza Mehrazin ${ }^{1}$, Mohammad Taghipour ${ }^{1}$, Omid froutan ${ }^{1}$, Bashir Ghabdian $^{1} \&$ Hamid Soleimani ${ }^{2}$ \\ ${ }^{1}$ Department of Accounting, Neyshabur Branch, Islamic Azad University, Neyshabur, Iran \\ ${ }^{2}$ Faculty of Economics and Business Administration, Ferdowsi University of Mashhad (FUM), Iran \\ Correspondence: Mohammad Taghipour, Department of Accounting, Neyshabur Branch, Islamic Azad \\ University, Neyshabur, Iran. E-mail: m.taghipour40@gmail.com
}

Received: April 19, 2013

Accepted: June 17, 2013

Online Published: July 26, 2013

doi:10.5539/ibr.v6n8p121

URL: http://dx.doi.org/10.5539/ibr.v6n8p121

\begin{abstract}
Development of financial markets and consequences of economic crises at international level caused effects on job environment and the companies' future financial situation is a vital factor for different beneficiary groups, bankruptcy prediction can be used a mean to help them. Prediction methods are constantly evolving, and artificial neural networks have nowadays found a special position among these methods. Since learning constitutes a significant part of neural network models, learning methods of training these models are of particular importance. Therefore, finding a proper training method to reach the desired goals is necessary. Thus, this study seeks to find a better method of building and training artificial neural networks which leads to more accurate predictions of bankruptcy. Meanwhile, three neural networks of radial basis function type were built and trained separately by Altman model (1983), Zmijewski model (1984) and combinatory models' variables. After evaluating the ability of these three models of bankruptcy prediction, their accuracy has been compared. Time span of 2004 to 2012 (eight years) has been used to select samples from the listed companies in Tehran Stock Exchange. Results show that all three models have the ability of predicting bankruptcy and the model trained with Altman Model's variables is more accurate than the other two models in this regard.
\end{abstract}

Keywords: artificial intelligence, artificial neural network, radial basis function, bankruptcy, alpha error, beta error

\section{Introduction}

In one of the first academic studies of bankruptcy theory, bankruptcy has been defined as a company's unprofitability which increases the probability of the company's inability to repay its principal debt and its interest (Gordon, 1971). In another definition, bankruptcy is considered a situation in which a company's cash flows are less than its total interest costs of long-term debt (Whitaker, 1999).

Bankruptcy takes place when a company suffers a lot of losses or it fails to repay its debts. Failure in repaying debts happens when the proportion of a company's assets and debts wipes out (Chen \& $\mathrm{Du}, 2009$ ) and the company fails to repay its debts.

In one of the first academic studies of bankruptcy field, bankruptcy has been defined as company's unprofitability which increases the probability of the company's inability to repay its principal debt and its interest (Gordon, 1971). In another definition, bankruptcy is considered a situation in which a company's cash flows are less than its total interest costs of long-term debt (Whitaker, 1999). Bankruptcy occurs when a company suffers a lot of losses or fails to repay its debts. Failure in repaying debts happens when the proportion of a company's assets and debts wipes out (Chen \& $\mathrm{Du}, 2009)$ and the company fails to repay its debts.

Bankruptcy prediction is one of the methods which can be used to contribute to suitable utilization of investment opportunities and better allocation of resources. Prediction estimates the probability of future events based on present and past information. Thus it first provides the companies with necessary warnings to be vigilant of bankruptcy and take appropriate measures regarding this issue; and second, it makes the investors and creditors recognize favorable investment opportunities from unfavorable ones and invest their resources in suitable opportunities. Therefore, companies' bankruptcy prediction has always been one of the notable issues for investors, creditors, and the government (Jones, 1987), and the auditors' attention should not be ignored in this 
regard. Bankruptcy can be studied through the bankrupt companies' careful examination of financial ratios; these ratios reflect interactive effects of external and internal elements on a company's poor financial situation. Using financial ratios traditional risk analysis determines signals associated with a company's movement toward financial distress or bankruptcy before declaring bankruptcy. Since Beaver's preliminary study (1996), which introduced the first model in bankruptcy field financial ratios analysis has become the dominant approach of examining companies' bankruptcy characteristics.

\subsection{Bankruptcy Prediction}

The techniques used for developing bankruptcy prediction models are classified into three groups: statistical models, artificial intelligence, and theoretical models.

"Bankruptcy" is a legally declared inability or impairment of ability of an individual or organizations to pay their creditors. Creditors may file a bankruptcy petition against a debtor in an effort to recoup a portion of what they are owed. Bankruptcy prediction is very important because it serves two main purposes under the bankruptcy law. First, bankruptcy law gives creditors some payment on their debts if a debtor (the one who owes the debt) can afford to pay them. Second, bankruptcy law gives debtors a fresh start, by cancelling many of their debts, through an order of the court called a discharge. If an organization is not willing to get into such an adverse circumstances, then one can have sound bankruptcy prediction techniques in place.

Bankruptcy prediction has become increasingly important over the last few decades. The number of corporate bankruptcies has been growing ever since the economical depression of 1930. Bankruptcy prediction is a classification problem, with two classes: bankrupt or non-bankrupt (healthy). Over the past few decades financial crisis was observed in some emerging sectors like banking. Bankruptcy prediction of banks has been an extensively researched area since late 1960s. Bankruptcy can affect all the areas where the sufferers are creditors, auditors, stock holders and senior management. So, they are all interested in predicting the bankruptcy. Researchers used CAMELS rating for prediction in the early days. But, because of its in effectiveness they moved towards other theoretical models.

\subsection{Bankruptcy Prediction with Neural Networks}

Recently, the most promising area of research in bankruptcy prediction is Artificial Neural Networks (ANN). Artificial neural network is a kind of information processing model in which natural or biological neural systems have been inspired. Artificial neural networks are among those dynamic systems that transmit knowledge or rules behind the data to the network structure through processing experimental data. ANNs are mimicry of human brain reasoning using patterns of and relationships among data to train element processing (Haykin, 1999). ANNs have been studied extensively as a useful tool in many business applications including bankruptcy prediction. In this section, we present a rather comprehensive review of the literature on the use of ANNs in bankruptcy prediction. The ${ }^{\circledR}$ rst attempt to use ANNs to predict bankruptcy is made by Odom and Sharda. In their study, three-layer feedforward networks are used and the results are compared to those of multi-variate discriminant analysis. Using dierent ratios of bankrupt rms to nonbankrupt ${ }^{\circledR}$ rms in training samples, they test the eects of dierent mixture level on the predictive capability of neural networks and discriminant analysis. Neural networks are found to be more accurate and robust in both training and test results. During the past years neural networks have been emerged as a technology which can identify and model data patterns; a task that is not easily possible through traditional statistical methods. Neural networks have been largely seen as a black box which defines the complex pattern of the relationship among the data, and learning through training is one of its basic features.

\section{Review of Related Literature}

Paula M. Weller (2010) has conducted a test of several models of artificial networks and multiple and probit analysis to predict bankruptcy of United States of America's textile industry. In this study, financial data of 47 bankrupt companies and 104 public shares non-bankrupt companies of textile industry has been examined during the years of 1998 to 2004 which includes Asia's currency crisis and competition increase on behalf of China. Results show that in case of bankrupt companies, Altman model (1968) and neural network model based on its variables has the most prediction ability for one or two years prior to bankruptcy; and neural network model based on Zmijewski's variables (1984) and also neural network model based on Altman variables (1983) show the best classification results in case of non-bankrupt companies during the entire period of research. Hung \& Chen's study (2009) deals with the prediction of companies' bankruptcy probability using Decision Tree Algorithm, back propagation neural network and Support Vector techniques and shows that back propagation neural network has had a better performance than the other two methods. In this study, bankruptcy prediction model based on decision tree and support vector techniques has had an accuracy equivalent to $70 \%$ and $70.89 \%$ 
respectively, while back propagation neural network model has had an accuracy equivalent to $72.37 \%$. Sungbincho, Kim and Kwon Bae's study (2009) compares logit bankruptcy prediction model, artificial neural network, combinatory multiple discriminant analysis, decision tree, support vector technique and combinatory neural network to each other and presents a combinatory model of bankruptcy prediction using neural network learning. Its results show that artificial neural network has a better performance than the other models in case of classification accuracy. Average prediction accuracy of the aforementioned models are listed as $78.04 \%, 78.01 \%$, $78.15 \%, 72.38 \%, 78.01 \%$, and $78.92 \%$ respectively. Using fuzzy logic techniques, Slim (2007) presents a bankruptcy prediction model in his study and believes that this prediction method has a better predicting performance than the other methods like back propagation neural network and linear discriminant analysis. In this study 17 financial ratios of 68 companies from 2000 to 2005 have been used. The result of using five layer fuzzy neural networks confirms researcher's reasoning. In average, bankruptcy prediction accuracy of linear discriminant analysis, back propagation neural network, and fuzzy neural network models in the training sample have been $70.83 \%, 81.92 \%$, and $97.92 \%$ respectively, and in the test sample have been $60 \%, 70 \%$, and $90 \%$ respectively. This shows that fuzzy neural network has had a better performance in case of prediction accuracy in both training and test samples. Kim and Gu's study (2006) deals with the comparison of performance accuracy to predict bankruptcy of two models of multiple discriminant analysis and logit analysis using financial data of 36 bankrupt and non-bankrupt companies from 1986 to 1998. 12 independent variables have been used including financial ratios and the results show that logit model's performance accuracy to predict bankruptcy has been $93 \%$ which is the same as that of multiple discriminant analysis and they both have had similar performance.

\section{Research Hypotheses}

Seeking to find a suitable model to identify bankrupt and non-bankrupt companies from each other with the lowest level of error possible and fast application is of significant importance. Hence, in this research, in order to measure the ability and compare the accuracy of the models used:

1) Radial neural network model is able to predict bankruptcy using Altman's variables.

2) Radial neural network model is able to predict bankruptcy using Zmijewski's variables.

3) Radial neural network model is able to predict bankruptcy using Altman, Zmijewski's variables and two extra variables of total assets and sales avenue.

4) Error type I rate is equal among radial neural network models based on Altman, Zmijewski, and combinatory models.

5) Error type II rate is equal among radial neural network models based on Altman, Zmijewski, and combinatory models.

\section{Research Methodology}

In this inductive research, cross-sectional data has been used. Artificial nerve is a model whose components are very similar to real nerve components. This has first been presented by McCullough and Pitts (1943). Neural networks consist of a series of layers of simple processing elements called neurons which work parallel. Each input layer is connected to one or more middle layers and the middle layers are also connected to output layer where the network's response is appeared as system output. A striking feature of neural networks is their learning capability. They are able to modify their existing weights of defined relationships each time in accordance with each input sample. There are different types of neural networks, One of the most important is Radial Basis Function. Taking its diverse applications into account, radial basis function has become one of the most popular neural networks and is considered as the main competitor of Multilayer Perceptron. These networks have taken their greatest inspirations from statistical techniques of patterns classification. This study can be considered a survey research in terms of statistics, modeling, and research methodology. It deals with building and comparing the research models (three models) to predict bankruptcy of the companies listed in Tehran Stock Exchange using artificial neural network.

Profile (1) is a view of an artificial nerve. Input signals which have been specified by $\mathrm{X}_{0}, \mathrm{X}_{1}, \ldots, \mathrm{X}_{5}$ are continuous variables. Each one of these input values are influenced by a certain weight. These processing elements (nerve) are composed of two parts. The first part adds weighted input together and gives a quantity named I; the second part is a non-linear filter, which is called activation function, through which the output is determined (Ghazanfari \& Kazemi, 1382).

\section{Fitting process of each model is as following:}

1) Using research's desired financial ratios to train artificial neural network, 
2) Separating two samples of bankrupt and non-bankrupt companies using article 141 of the Commercial Code,

3) Using neural networks with radial basis function to build research's models,

4) Results examination and performance accuracy comparison of the built models.

\section{Research Population and Statistical Samples}

The population under study in this research has been the listed companies in Tehran Stock Exchange. Systematic elimination method has been used to select the sample, 66 companies remained out of 431 companies to test research hypotheses, half of which were bankrupt and the other half non-bankrupt. Samples must have the following features in order to be consistent:

1) Ending their fiscal period in December,

2) Not belonging to the class of financial intermediate companies,

3) Being subject to article 141 of Iran's Commercial Code in case of the bankrupt group,

4) Revealing all needed data of the research.

\section{Research Variables and Model Design}

Radial function (radial basis), which is briefly called RBF, has a lot of advantages over multilayer perceptron (MLP) including higher speed and creating better decision-making limitations. One more advantage is that the RBF network is far easier to interpret the outer layer than MLP. RBF's main architecture constitutes of a three layer network which you can see in the picture of the next page. The input layer is just a slot layer and no processing is done there. The second layer or the hidden layer establishes a non-linear adjustment between the input and output environment usually with a larger dimension in which the patterns are linearly separable. Finally, the third layer produces the total weight accompanied with a linear output. If the RBF is used for function approximation, such an output is efficient; while if there is a need for patterns' classification, then a hard limiter or a sigmoid function can be placed on output nerves to produce output values.

The individual characteristic of RBF is the process that is done in the hidden layer. The basic idea is that the patterns of the input environment form a cluster. If the centers of these clusters are clear, the distance from cluster centers can be measured. Furthermore, this distance measurement is performed in a non-linear way; therefore, if there is a pattern in adjacent area of a cluster center, the value is much closer to production. Out of this area, the value obtained is significantly reduced. The important point is that this area is radially symmetric around the cluster center, thus the non-linear function changes into a known radial basis function. The most common picture of a radial basis function is as follows:

$$
\emptyset(\mathrm{r})=\exp \left(-\frac{r^{2}}{2 \sigma^{2}}\right)
$$

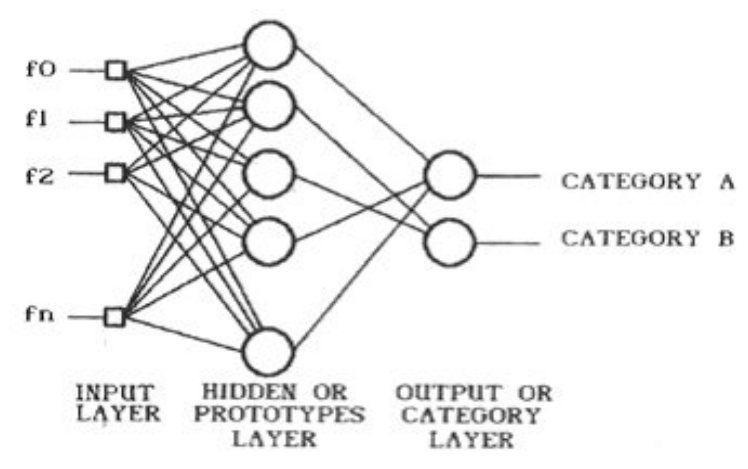

Figure 1. Picture of radial basis function

In a RBF, $r$ is the numeric value of the distance from cluster center. Generally, the measured distance to cluster center is a Euclidean distance. For each nerve in the hidden layer, weights represent the coordinates of cluster center. Therefore, when a nerve receives a $\mathrm{x}$ input pattern, the distance is measured using the following equation:

$$
r_{j}=\sqrt{\sum_{i=1}^{n}\left(x_{i}-w_{i j}\right)^{2}}
$$


Therefore the output of $\mathrm{J}$ nerve in the hidden layer is like this:

$$
\emptyset_{j}=\exp \frac{\left(-\sum_{n=1}^{n}\left(x_{i}-w_{i j}\right)\right)^{2}}{2 \sigma^{2}}
$$

$\sigma$ variable is defined as the width or radius of normal curve, and sometimes it is necessarily determined in an empirical way. When the distance from normal curve center reaches to $\sigma$, the output will degrade from 1 to 0.6 .

Since it is believed that financial ratios reflect interactive effects of external and internal elements on a company's bad financial situation, financial ratios have been used to train and test the models in this research.

Altman (1968) is the first person who delivered multivariate bankruptcy prediction models. Applying multiple discriminant analysis method and using financial ratios as independent variables, he sought agencies' bankruptcy prediction. He presented his popular model as Z-score model which is famous in commercial bankruptcy prediction. Using this approach, he selected five ratios among 22 financial ratios which have been the best ratios to predict bankruptcy in his opinion. Combining these five ratios together, Altman presented a model which, he believed, had the best performance among other financial ratios. In the following years, Z-score model met with some criticisms. Analysts, accountants, and even managers believed that Z-score model was only applicable for public institutions. In the rest of his studies, Altman succeeded to modify and correct faults of his model and presented his z' new model in which the variables had been selected as follows:

$\mathrm{X}_{1}$ - Working Capital / Total Assets

$\mathrm{X}_{2}$ - Cumulative Profit / Total Assets

$\mathrm{X}_{3}$ - Earning Before Interest and Taxes / Total Assets

$\mathrm{X}_{4}$ - Market Value of Equity / Total Debts

$\mathrm{X}_{5}-$ Sales / Total Assets

After modifying or adjusting the initial model to adapt to private companies by replacing the book value of equity with the market value of equity in $\mathrm{X}_{4}$ variable, Altman modifies the formula to be applicable for non-manufacturing companies as well in which the variables are as follows:

$\mathrm{X}_{1}-$ Net Profit / Total Assets

$\mathrm{X}_{2}$ - Total Debts / Total Assets

$\mathrm{X}_{3}-$ Current Debts / Current Assets

This model is one of the simplest models of bankruptcy prediction which has well respected the principle of low number of independent variables in models.

Variables of this research are of three types which are presented as the following:

A) Independent variables: Financial ratios used in Altman Model (1983), financial ratios used in Zmijewski model which have been introduced before and are derived from financial statements of manufacturing companies listed in Tehran Stock Exchange.

B) Control variables: Two variables of common logarithm of total assets and sales revenue are used to determine the effect of companies' size.

C) Dependent variables: It is a virtual variable which takes either one of the two values of zero or one (non-bankrupt or bankrupt, respectively).

\section{The Process of Testing Hypotheses}

In order to test the hypotheses, after collecting and transmitting data to Excel software (2010) and initial classification, the data (independent variables) were transmitted to IBM SPSS Statistics 19 software to build three different models using artificial networks and radial basis functions. Then they were compared to each other with McNemar and Fisher's exact statistical tests.

In the design of neural network of all three models, the samples were separated equally and respectively: $60 \%$ as training data, $30 \%$ as test data, and $10 \%$ as hold out sample for the final network test. Softmax activator function was used for absolute dependent variables in all three networks because of its better performance whose form is as follows: 
$\gamma$ is the value of output nodes and $c$ is the net input data for output nodes.

This function takes real values from the previous layer and converts them to a vector whose elements fall in the range of $(0,1)$ and their sum be 1 . Radial basis neural networks have a hidden layer and the number of nodes is automatically selected by the network (Norusis, 2011).

The rest of this part deals with fitting description of research hypotheses where three first hypotheses test the ability of the built models, and the two final hypotheses compare the models' accuracy to each other.

\subsection{Fitting Description of Hypotheses One to Three}

After adjustments and implementation of artificial neural network building which were the same for all three models, the first model constituted of 4 input nodes in the first layer which are Altman model's independent variables in neural network, 10 nodes in the hidden layer, and 2 output nodes which are the separation of bankrupt and non-bankrupt companies. The second model constituted of 3 input nodes in the first layer which are Zmijewski model's independent variables in neural network, 8 nodes in the hidden layer, and 2 output nodes. The third model constituted of 8 input nodes in the first layer which are the combinatory independent variables of Altman and Zmijewski models, and two extra variables of companies' size, 7 nodes in the hidden layer, and 2 output nodes.

\subsection{Fitting Description of Hypotheses Four and Five}

In these two hypotheses, the researcher seeks to evaluate the accuracy and validity of the predictions of neural network model and compare the accuracy of these three models to each other. To this end, error type I (alpha) and II (beta) of each one of these three models were measured and compared to each other. The low level of each one of these errors for each model is equal to its higher accuracy. Alpha error means inaccurate determination of non-bankruptcy, which means that the company is non-bankrupt and is in a good situation while the estimating model considers it bankrupt. Beta error means inaccurate determination of bankruptcy, which means that although the company is bankrupt, the estimating model considers it non-bankrupt.

\subsection{Testing Hypothesis One}

Hypothesis one is evaluated by McNemar and Fisher's exact statistical tests and the result is as follows:

As it is perceived in Table 1, the valid values of dependent variable predicted by $95 \%$ confidence interval are not independent of one another. The model has prediction accuracy of $94.2 \%$ for bankrupt companies and $92.4 \%$ for non-bankrupt companies. Moreover, there is a significant difference among the model's errors and the research hypothesis is accepted.

Table 1. Statistical results of testing hypothesis one

\begin{tabular}{lll}
\hline & Trained Artificial Neural Network Based on Altman Model's Variables (1983) \\
\hline Results & Probability Rate & Null Hypothesis of Statistical Test \\
Fisher's Exact Test & 0.000 & $\mathrm{H}_{0}: \mathrm{P}_{1}=\mathrm{P}_{2}$ \\
McNemar Test & 0.678 & $\mathrm{H}_{0}: \mu_{\mathrm{D}}=0$ \\
Prediction Accuracy & Non-bankrupt Companies & Bankrupt Companies \\
& $92.4 \%$ & $94.2 \%$ \\
\hline
\end{tabular}

\subsection{Testing Hypothesis Two}

Hypothesis two is evaluated by McNemar and Fisher's exact statistical tests and the result is as follows:

As it is perceived in table 2, the valid values of dependent variable predicted by $95 \%$ confidence interval are not independent of one another. The model has prediction accuracy of $81.4 \%$ for bankrupt companies and $86 \%$ for non-bankrupt companies. Moreover, there is a significant difference among the model's errors and the research hypothesis is accepted.

Table 2. Statistical results of testing hypothesis two

\begin{tabular}{lll}
\hline & Trained Artificial Neural Network Based on Zmijewski Model's Variables (1984) \\
\hline Results & Probability Rate & Null Hypothesis of Statistical Test \\
Fisher's Exact Test & 0.000 & $\mathrm{H}_{0}: \mathrm{P}_{1}=\mathrm{P}_{2}$ \\
McNemar Test & 0.350 & $\mathrm{H}_{0}: \mu_{\mathrm{D}}=0$ \\
Prediction Accuracy & Non-bankrupt Companies & Bankrupt Companies \\
& $86 \%$ & $81.4 \%$ \\
\hline
\end{tabular}




\subsection{Testing Hypothesis Three}

Hypothesis three is evaluated by McNemar and Fisher's exact statistical tests and the result is as follows:

As it is perceived in table 3, the valid values of dependent variable predicted by $95 \%$ confidence interval are not independent of one another. The model has prediction accuracy of $87.8 \%$ for bankrupt companies and $93 \%$ for non-bankrupt companies. Moreover, there is a significant difference among the model's errors and the research hypothesis is accepted.

Table 3. Statistical results of testing hypothesis three

\begin{tabular}{lll}
\hline & Trained Artificial Neural Network Based on Combinatory Model's Variables \\
\hline Results & Probability Rate & Null Hypothesis of Statistical Test \\
Fisher's Exact Test & 0.000 & $\mathrm{H}_{0}: \mathrm{P}_{1}=\mathrm{P}_{2}$ \\
McNemar Test & 0.163 & $\mathrm{H}_{0}: \mu_{\mathrm{D}}=0$ \\
Prediction Accuracy & Non-bankrupt Companies & Bankrupt Companies \\
& $93 \%$ & $87.8 \%$ \\
\hline
\end{tabular}

\subsection{Testing Hypothesis Four}

Considering the above performed statistical tests, error type I (alpha) has been different in each one of these neural network models, it has been 7.6\% for trained neural network model based on Altman model's variables (1983), $14 \%$ for trained model based on Zmijewski model's variables (1984), and 7\% for trained model based on combinatory variables of these two models and the two variables of companies' size, as a result of which the hypothesis is rejected. Table 4 shows measured error type I rate for all three neural network models.

Table 4. Measured error type I rate

\begin{tabular}{llll}
\hline$\alpha$ & \multicolumn{3}{l}{ Trained Artificial Neural Network Based on Variables of ... } \\
\cline { 2 - 4 } & Altman Model (1983) & Zmijewski Model (1984) & Combinatory Model \\
\hline Error Type I (Alpha) & $7.6 \%$ & $14 \%$ & $7 \%$ \\
\hline
\end{tabular}

\subsection{Testing Hypothesis Five}

Considering the above performed statistical tests, error type II (beta) has been different in the first model of neural network from the other two models. It has been 5.8\% for trained neural network model based on Altman model's variables (1983), 18.6\% for trained model based on Zmijewski model's variables (1984), and $12.2 \%$ for trained model based on combinatory variables of these two models and the two variables of companies' size, as a result of which the hypothesis is rejected. Table 5 shows measured error type II rate for all three neural network models.

Table 5. Measured error type II rate

\begin{tabular}{llll}
\hline \multirow{2}{*}{$\beta$} & \multicolumn{4}{l}{ Trained Artificial Neural Network Based on Variables of ... } \\
\cline { 2 - 4 } & Altman Model (1983) & Zmijewski Model (1984) & Combinatory Model \\
\hline Error Type II (Beta) & $5.8 \%$ & $18.6 \%$ & $12.2 \%$ \\
\hline
\end{tabular}

\section{Conclusion}

By increasing in number of corporations and variety of capital structure on one hand and clarifying the intensive financial crisis in Macro and Microeconomy on the other hand, creditors and beneficiaries of different firms are following to cover themselves to avoid the same risks. This fact informs them to use predictive models and applications to evaluate the financial ability of companies. The bankruptcy prediction can be used as an effective application to help them. The methods of prediction are being developed continually and the neural networks out of radial basis functions type have special position among these methods.

The results of this research show that all these three built artificial neural network have the ability to predict the bankruptcy of the companies under study, while the neural network trained by Altman model's variables (1983) is more accurate than the exact Fischer and MC Nemartest for $94.2 \%$ of bankcrupted companies and $92.4 \%$ of non bankcrupted companies. And thus this network has prediction error by $5.8 \%$ for bankrupted companies and $7.6 \%$ for non-bankrupted so there is no definitive difference in prediction of bankrupted companies situation in other words and totally this model has $93.3 \%$ of bankruptcy prediction capability, also the trained neural network by variables of Zmijewski (1984) by prediction accuracy of $83.7 \%$ has ability to predict the bankruptcy. The result of the third hypothesis is suggestive of the high prediction ability of bankruptcy. This model by prediction accuracy 
rate of $93 \%$ for non-bankrupted and $87.8 \%$ for bankrupted companies has better accuracy than the Zmijewski model variables (1984).totally the results of the research shows the accuracy of radial basis of neural network based on Altman model's variables in bankruptcy prediction in comparison with the Zmijewski model (1984) and the combined model.

Table 6. A Summary of the results obtained from models' evaluation

\begin{tabular}{llll}
\hline \multirow{2}{*}{ Prediction Accuracy } & \multicolumn{3}{l}{ Trained Artificial Neural Network Based on Variables of ... } \\
\cline { 2 - 4 } & Altman Model (1983) & Zmijewski Model (1984) & Combinatory Model \\
\hline Non-bankrupt Companies & $92.4 \%$ & $86 \%$ & $93 \%$ \\
Bankrupt Companies & $94.2 \%$ & $81.4 \%$ & $87.8 \%$ \\
Error Type I (Alpha) & $7.6 \%$ & $14 \%$ & $7 \%$ \\
Error Type II (Beta) & $5.8 \%$ & $18.6 \%$ & $12.2 \%$ \\
\hline
\end{tabular}

\section{References}

Altman, E. I. (1983). Corporate Financial Distress: A Complete Guide to Predicting, Avoiding, and Dealing With Bankruptcy. New York: John Wiley \& Sons, Inc.

Beaver. W. H. (1966). Financial ratios as predictors of bankruptcy. Journal of Accounting Research, 4, 71-111. http://dx.doi.org/10.2307/2490171

Chen, W. S., \& Du, Y. K. (2009). Using neural networks and data mining techniques for the financial distress prediction model. Expert systems with applications, 36, 4075-4086. http://dx.doi.org/10.1016/j.eswa.2008.03.020

Gordon, M. J. (1971). Towards a Theory of Financial Distress. The Journal of Finance, 26, $347-356$. http://dx.doi.org/10.1016/j.eswa.2008.03.020

Haykin, S. (1999). Neural Networks: A Comprehensive Foundation (2nd ed.). Upper Saddle River, NJ: Prentice-Hall, Inc.

Hung, C., \& Chen, J. H. (2009). A selective ensemble based on expected probabilities for bankruptcy prediction. Expert Systems with Applications, 36(3), 5297-5303. http://dx.doi.org/10.1016/j.eswa.2008.06.068

Jones, F. J. (1987). Current Techniques in Bankruptcy Prediction. Journal of Accounting Literature, 6, 131-164.

Kim, H., \& Gu, Z. (2006). Predicting Restaurant bankruptcy: A Logit Model in comparison with a Discriminant Model. Journal of Hospitality Tourism research, 30, 474-793. http://dx.doi.org/10.1177/1096348006290114

McCulloch, W. S., \& Pitts, E. (1943). A Logical Calculus of the Ideas Immanent in Nervous Activity. Bulletin of Mathematical Biophysics, 5, 115-133. http://dx.doi.org/10.1007/BF02478259

Norusis, M. J. (2005). SPSS 13.0 Guide To Data Analysis.

Paula, M. W. (2010). The Application of Altman, Zmijewski and Neural Network Bankruptcy Prediction Models to Domestic Textile-Related Manufacturing Firms: A Comparative Analysis. A dissertation of H. Wayne Huizenga School of Business and Entrepreneurship Nova Southeastern University.

Slim, C. (2007). Fuzzy Neural Model for Bankruptcy Prediction. The Journal of Business Review Cambridge, $8(2), 117-122$.

Sungbin, C., Jinhwa, K., \& Jae, K. B. (2009). An integrative model with subject weight based on neural network learning for bankruptcy prediction. Expert Syst. Appl., 36(1), 403-410. http://dx.doi.org/10.1016/j.eswa.2007.09.060

Whitaker, R. (1999). The Early Stage of Financial Distress. Journal of Economics and Finance, 23(2), $123-133$. http://dx.doi.org/10.1007/BF02745946

Zmijewski, M. E. (1984). Methodological Issues Related to the Estimation of Financial Distress Prediction Models. Journal of Accounting Research, 24, 59-82. http://dx.doi.org/10.2307/2490859

\section{Copyrights}

Copyright for this article is retained by the author(s), with first publication rights granted to the journal.

This is an open-access article distributed under the terms and conditions of the Creative Commons Attribution license (http://creativecommons.org/licenses/by/3.0/). 